\title{
Implications of CD39 in immune-related diseases
}

\author{
Jianrui Zeng ${ }^{1}$, Zhaochen Ning ${ }^{1}$, Hui Zhang ${ }^{1}$, Guanjun Dong ${ }^{1}$, Junfeng Zhang ${ }^{1}$, Hui Shi ${ }^{1}$, \\ Fenglian Yan ${ }^{1}$, Mingsheng Zhao ${ }^{1}$, Changying Wang ${ }^{1}$, Qun Ma ${ }^{1}$, Jun Dai ${ }^{1}$, Zhihua Li $^{1}$, \\ Chunxia $\mathrm{Li}^{1}$, Haiyan Wang ${ }^{1}$, Dalei Cheng ${ }^{1}$, Yuzhong Wang ${ }^{2}$, and Huabao Xiong ${ }^{1}$ \\ ${ }^{1}$ Jining Medical University \\ ${ }^{2}$ Affiliated Hospital of Jining Medical University
}

August 11, 2020

\begin{abstract}
Extracellular adenosine triphosphate (eATP) mediates pro-inflammatory responses by recruiting and activating inflammatory cells. eATP is hydrolyzed by CD39 to adenosine monophosphate (AMP), which is converted to the immunosuppressive nucleoside adenosine (ADO) by CD73. CD39 is the rate-limiting enzyme in this cascade and can be viewed as an immunological switch that shifts ATP-driven pro-inflammatory immune cell activity to an anti-inflammatory state mediated by ADO. CD39 is expressed by a broad range of immune cells and can be influenced by genetic and environmental factors. Accumulating evidence suggests that CD39 is involved in several pathophysiological events, such as inflammatory bowel diseases, sepsis, ischemia-reperfusion injury, allergic diseases, systemic lupus erythematosus, diabetes, and cancer. Here, we focus on the current understanding of CD39 in immunity, and presents a comprehensive picture of the multiple roles of CD39 in a variety of disorders.
\end{abstract}

\section{Keywords: CD39, Inflammation, Cancer ATP and ADO signaling}

Extracellular ATP (eATP) plays an important role in regulating inflammation and immune responses; it is rapidly released through exocytosis during stress, cell injury, and death ${ }^{[1]}$. The effects of eATP are mediated by $\mathrm{P} 2$ cell-surface receptors (P2R), which include trans-cell membrane cationic channels (P2XR) and G-protein coupled receptors $(\mathrm{P} 2 \mathrm{YR})^{[2,3]}$. There are $7 \mathrm{P} 2 \mathrm{XR}$ and $8 \mathrm{P} 2 \mathrm{YR}$, which are expressed in almost all mammalian cells ${ }^{[4]}$. In addition to its metabolic functions, eATP is an important extracellular signal molecule that triggers and regulates a variety of inflammation-related processes. ATP is involved in the chemotaxis of inflammatory cells ${ }^{[5,6]}$, production of oxygen free radicals by neutrophils ${ }^{[7]}$ and production of cytokines by inflammatory cells ${ }^{[8]}$. CD39 is an enzyme that hydrolyzes eATP into adenosine monophosphate (AMP), and AMP is further converted by CD73 into nucleoside adenosine (ADO). Although the production of AMP is thought to be mainly mediated by CD39, AMP is also obtained through the transformation of $\mathrm{NAD}^{+}$by CD38 and CD203a ${ }^{[9-12]}$. The accumulated extracellular ADO performs its regulatory functions by binding to one of four $A D O$ receptors: $A_{1} R, A_{2 A} R, A_{2 B} R$, and $A_{3} R{ }^{[13}$, 14]. All four subtypes are members of the GPCR superfamily, and each subtype has a unique pharmacological profile, tissue distribution, and effector coupling ${ }^{[15]}$. Upon activation, Gi-coupled $\mathrm{A}_{1} \mathrm{R}$ and $\mathrm{A}_{3} \mathrm{R}$ inhibit adenylate cyclase and cyclic AMP (cAMP) production ${ }^{[16]}$ while Gs-coupled $\mathrm{A}_{2 \mathrm{~A}} \mathrm{R}$ and $\mathrm{A}_{2 \mathrm{~B}} \mathrm{R}$ stimulate cAMP synthesis and its downstream signaling pathways ${ }^{[17,18]}$. As a consequence, activation of $A_{2 A} R$ and $A_{2 B} R$ in immune cells induces strong immunosuppressive effects ${ }^{[19]}$. Finally, ADO is either removed from the extracellular space by ADO deaminase, which converts it into inosine, or is taken by nucleoside transporters back into the cell and converted back into AMP by ADO kinases ${ }^{[20]}$. CD39 is the rate-limiting enzyme in the ATP/ADPADO pathway. The expression of CD39 is regulated by pro-inflammatory cytokines, such as transforming 
growth factor- $\beta$ (TGF- $\beta$ ), interferons (IFNs), tumor necrosis factor- $\alpha$ (TNF- $\alpha$ ), interleukin-1 $\beta$ (IL-1 $\beta$ ), and prostaglandin E2 ${ }^{[21,22]}$, and processes, such as oxidative stress production and hypoxia ${ }^{[23,24]}$.

\section{The functions of CD39 in immune cells}

\section{CD39 and T-cells}

Within the T-cell population, CD39 is mainly expressed by CD4+ lymphocytes and mainly by regulatory Tcell (Treg) subsets ${ }^{[25]}$. The expression of CD39 in CD4 ${ }^{+}$T-cells increases with age and CD39 ${ }^{+} \mathrm{CD} 4^{+}$T-cells were found to be prone to apoptosis and metabolic stress ${ }^{[26]}$. Both CD39 and CD73 are expressed in Tregs and hydrolyze pericellular ATP into ADO, which contributes to Treg immune suppressive functions ${ }^{[27,28]}$. Previous reports indicated that $90 \%$ of human Foxp3 ${ }^{+}$Tregs are CD $39^{+[25,29]}$. Initial phenotypic and functional analyses demonstrated that $\mathrm{CD} 4{ }^{+} \mathrm{CD} 25^{\text {high }} \mathrm{CD} 39^{+} \mathrm{CD} 45 \mathrm{RO}^{+}$cells had properties consistent with effector Treg, CD4 ${ }^{+} \mathrm{CD} 25^{\text {high }}{ }^{-}$D $39^{-} \mathrm{CD} 45 \mathrm{RO}^{-}$cells were naïve Tregs, and CD4 ${ }^{+} \mathrm{CD} 25^{\text {high }} \mathrm{CD} 39^{-} \mathrm{CD} 45 \mathrm{RO}^{+}$cells were predominantly non-Tregs with effector T-cell functions ${ }^{[30]}$. CD $39^{+}$Treg cells demonstrated more potent suppressive abilities compared to conventional Treg cells. Tregs induced by CD39 ${ }^{+}$naive T-cells, CD39 ${ }^{+}$ iTregs, demonstrate enhanced proliferation and suppressive abilities ${ }^{[31]}$. CD8 ${ }^{+}$iTregs displayed increased CD39 expression in patients with systemic lupus erythematosus (SLE) nephritis, which was shown to play an important role in the suppressive function of human $\mathrm{CD} 8^{+}$iTregs ${ }^{[32]}$. CD39 ${ }^{\text {high }}$ Tregs were more stable and functional than CD39 ${ }^{\text {low }}$ Tregs. Cultured CD $39^{\text {high }}$ Tregs maintained stable forkhead box protein 3 (Foxp3) expression, whereas CD39 ${ }^{\text {low }}$ Tregs lost Foxp3 expression and trans-differentiated into Th1 or Th17 cells. Furthermore, human $\mathrm{CD} 4^{+} \mathrm{CD} 39^{\text {high }}$ Tregs, but not $\mathrm{CD} 4^{+} \mathrm{CD} 39^{\text {low }}$ Tregs, protected against xenograftversus-host-disease in mice models ${ }^{[33]}$. Mouse Tregs showed increased CD39 activity only when their T-cell receptor (TCR) was activated, while the CD39 enzyme was found to be ineffective in unstimulated cells ${ }^{[34]}$. CD39 is also highly expressed in tumor-infiltrating Tregs and participates in Tregs-mediated immunosuppression ${ }^{[35-37]}$. Some CD4 ${ }^{+} \mathrm{T}$ cells do not express FoxP3, but express CD39 ${ }^{[25,38]}$. These T-cells have a unique phenotype called the memory effect, and they have no immunosuppressive capacities.

CD39 is also expressed in $\mathrm{CD}^{+}$cells. It was reported to be highly expressed in a variety of human tumorinfiltrating $\mathrm{CD}^{+}$T-cells found in renal cancer, gastric cancer ${ }^{[39]}$, lung cancer, colorectal cancer, breast cancer ${ }^{[40]}$ and head and neck cancer ${ }^{[41]}$. Tumor-infiltrating CD $39^{\text {high }} \mathrm{CD} 8^{+}$T-cells increase with tumor growth and exhibit features of exhaustion ${ }^{[40]}$. CD $39^{+} \mathrm{CD} 8^{+} \mathrm{Tc} 1$ cells limit interferon- $\gamma($ IFN- $\gamma$ ) production of $\mathrm{CD} 39^{-} \mathrm{CD} 8^{+} \mathrm{T}$-cells by generating ADO, which acts in a paracrine manner ${ }^{[42]}$.

CD39 is expressed on Th17 cells, and co-expression of CD39 and CD161 by CD4 ${ }^{+}$T-cells might serve as a biomarker to monitor Th17 responsiveness ${ }^{[43]}$. The expression of CD39 and CD73 on the surface of Th17 cells is closely regulated by IL-6 and TGF- $\beta$, which induce Th17 differentiation ${ }^{[44]}$. Furthermore, CD39 activity regulates the conversion of Th17 cells into IL-10-producing cells in vitro, which is abrogated in the presence of ATP and the CD39-specific inhibitor ARL67156 ${ }^{[45]}$. In a mouse cancer model, Th17 cells produced in the presence of TGF- $\beta$ were shown to have high expression levels of CD39 and CD73, which inhibit T-cell response and promote tumor growth in an ADO-dependent manner ${ }^{[44]}$. Moreover, CD39 ${ }^{+}$ Th17 cells in juvenile autoimmune liver disease (AILD) are both quantitatively decreased and qualitatively deficient. Low expression levels of CD39 and $\mathrm{A}_{2} \mathrm{AR}$ may contribute to the perpetuation of Th17 cell effector properties and unfettered inflammation in this disease ${ }^{[46]}$.

CD39 is also expressed in other types of T cells. Tissue-resident memory T-cells (Trm) express high levels of PD-1, TIGIT, and CD39 and represent tumor-reactive tumor-infiltrating lymphocytes ${ }^{[4]}$. CD39 has been reported as a surface marker of mouse regulatory $\gamma \delta \mathrm{T}$-cells, which have been shown to suppress contact hypersensitivity ${ }^{[48]}$.

\section{CD39 and B cells}

The expression of CD39 is ubiquitous in B cells; however, CD73 expression is uncommon. In certain mouse strains, approximately $30-50 \%$ of B-1 cells $\left(\mathrm{B} 220^{+} \mathrm{CD} 23^{-}\right)$and IL-10 producing B (B10) cells $\left(\mathrm{B} 220^{+} \mathrm{CD} 5^{+} \mathrm{CD} 1 \mathrm{~d}^{\text {high }}\right)$ are $\mathrm{CD} 73^{\text {high }}$, whereas few conventional B-2 cells $\left(\mathrm{B} 220^{+} \mathrm{CD} 23^{+} \mathrm{AA} 4.1^{-}\right)$express 
CD73. In keeping with expression of both CD73 and CD39, CD73 ${ }^{+} \mathrm{B}$ cells produce ADO in the presence of ATP substrate, whereas B-2 cells do not ${ }^{[49]}$. Figueiro et al. defined CD39 ${ }^{\text {high }}$ B cells as the major contributor to the regulatory network operated by human B lymphocytes ${ }^{[50]}$. CD39 ${ }^{\text {high }}$ B cells co-cultured with autologous effector T cells suppressed T-cell activation/proliferation and increased the secreted levels of IL-6 and IL-10. The proliferation and functions of these CD39 ${ }^{\text {high }} \mathrm{B}$ cells are regulated by $\mathrm{A}_{1} \mathrm{R}-$ and $\mathrm{A}_{2 \mathrm{~A}} \mathrm{R}-$ mediated autocrine signaling. Saze et al. found that the production of AMP and ADO by CD $39^{+} \mathrm{CD} 73^{+} \mathrm{B}$ cell subsets is related to the control of CD4 and CD8 effector immunity ${ }^{[51]}$. The absence of CD39 did not change the number of B cells in peripheral blood and spleen. However, CD $39^{-/-}$mice showed impaired B cell memory response to T-dependent, suggesting that CD39 may contribute to the antibody affinity maturation and the post-germinal centers $\mathrm{B}$ cell differentiation ${ }^{[52]}$.

B cells express P2XR and P2YR ${ }^{[53]}$ which allows ATP to regulate B cell activation, adhesion, migration, and IgE secretion ${ }^{[54]}$. ATP-driven P2X7R activation is crucial for secretion of IgM, indicating that this receptor plays a key role in the humoral response ${ }^{[55]}$. It can be speculated that CD39 may affect the ATP-mediated $\mathrm{B}$ cell regulation.

\section{CD39 and neutrophils}

CD39 is widely expressed in neutrophils and plays a key role in regulating neutrophil activity by controlling the extracellular purine energy gradient ${ }^{[56]}$. In addition, neutrophils express CD73 ${ }^{[57]}$ and all four ADO receptors ${ }^{[58]}$. Neutrophils directly secrete ADO and inhibit its degradation. Furthermore, they release ATP following activation, which is subsequently hydrolyzed by CD39 and CD73 into ADO ${ }^{[59]}$. The inadequate activity of the CD39/CD73 axis is related to the amplification and uncontrolled activation of neutrophils [60], enhancement of their chemotactic function ${ }^{[61]}$, and increased neutrophil adhesion to the vascular endothelium $[60,62]$.

Studies have shown that CD39 plays an important role in regulating neutrophil chemotaxis by facilitating the hydrolysis of eATP. Shah et al. demonstrated that eATP had a regulatory effect on the late stage of neutrophil recruitment ${ }^{[63]}$. Once neutrophils reach the ATP-rich region, blocking CD39 may promote the stop signal of neutrophil chemotaxis ${ }^{[64]}$. Chen et al. showed that hydrolysis of ATP by CD39 promoted neutrophil chemotaxis by activating the A3R ${ }^{[5]}$. Both A3R- and CD39-deficient mice showed impaired recruitment of neutrophils to inflammatory sites ${ }^{[61,65]}$. Paradoxically, lipopolysaccharides (LPS)-induced accumulation of neutrophil into the lungs was enhanced in CD39-/- mice, which may be due to the loss of normal endothelial barrier and increased capillary leakage in CD39-/- mice ${ }^{[66]}$.

\section{CD39 and NK cells}

It has been reported that the expression of CD39 is very low in resting human NK cells ${ }^{[56]}$. In murine NK cells, CD39 is the dominant ectonucleotidase and thereby plays a predominant role in the regulation of pericellular nucleotide concentration levels. While murine NK cells do not express CD73 and cannot efficiently generate ADO, they primarily mediate ATP and ADP hydrolysis into AMP ${ }^{[67]}$. However, the human NK cells were shown to produce ADO via a CD38-mediated pathway ${ }^{[68]}$.

CD39 deficiency and changes in P2 receptor activation abrogate secretion of interferon gamma by NK cells in response to inflammatory mediators, and limiting tissue damage mediated by these innate immune cells during IRI ${ }^{[67]}$. In addition, CD39 deletion has been shown to have a protective effect in the context of concanavalin A hepatitis induced by NKT cells ${ }^{[69]}$. Additional protective effects of CD39 deletion have been demonstrated in the context of invariant NKT cell-mediated hyperoxic acute lung injury ${ }^{[70]}$. After trauma, the subsets of NK cells changed significantly, and the expression of surface CD39 increased in those NK cells. The observed post-injury increase in CD39 expression levels in NK cells provides an explanation for the susceptibility to infection of those patients, and it might represent a potential prognostic marker or drug target ${ }^{[71]}$.

In a tumor setting, the expression of CD39 and the consequential ATP hydrolysis and ADO generation compromise anti-tumor immune responses, including those that may be mediated by NK cells. Zhang et al. 
showed that both CD39 and CD73 are up-regulated in lung tumor-infiltrating NK cells [72]. Furthermore, the same study demonstrated that NTPDase inhibitor sodium polyoxotungstate (POM-1) enhanced NK cell-mediated metastatic control and synergized with combined Braf and MEK inhibition, recombinant IL-2, or anti-PD-1 and anti-CTLA-4 checkpoint blockade. Moreover, Yan et al. showed that the anti-metastatic activity of anti-CD39 was NK cell- and IFN- $\gamma$-dependent and that the quantity of IFN- $\gamma$ produced in lunginfiltrating NK cells was enhanced following tumor challenge and anti-CD39 therapy ${ }^{[73]}$.

\section{CD39 and dendritic cells (DCs)}

CD39 is expressed in both human and mouse DCs [74, 75]. Mouse bone marrow-derived DCs constitutively express CD39 but do not express CD73; thus, AMP is not converted into ADO ${ }^{[76]}$. The net effect of CD39 on the regulation of DC function may be determined by a number of factors, including the balance of P2XR and P2YR expression in specific DC populations and the concentration of local eATP, ADP, and certain nucleotides. Mizumoto et al. demonstrated that CD39 expression on dendritic cells is required for the optimal stimulation of hapten-reactive T-cells ${ }^{[75]}$. CD39 is considered necessary to prevent desensitization of the P2 receptor, which is required for the optimal function of DCs. Langerhans cells are a type of epithelial dendritic cells, which are characterized by high expression levels of CD39 and show a decrease in antigen presentation ability in the absence of CD $39^{[75]}$. CD $39^{-/-}$mice have major defects in dendritic cell formation, antigen presentation, and response to semi-antigens ${ }^{[77]}$. Dwyer et al. proposed that the functional defect of CD39-/- dendritic cells is due to its impaired ability to initiate and maintain cell-cell contact, and that CD39 might be transferred to immune synapses to facilitate cell contact signals during antigen presentation [52]. On the contrary, Yoshida et al. showed that CD39-deficient hepatic dendritic cells exhibit more mature phenotypes, stronger responsiveness to TLR ligands, and stronger pro-inflammatory and immunostimulatory activities ${ }^{[78]}$. IL-27 can up-regulate CD39 on the surface of DC and then reducing the concentration of ATP and the activation of NLRP3 inflammatory bodies, thus limiting the differentiation of Th1 and Th17 cells and promoting immune tolerance ${ }^{[79]}$. LPS can down-regulated membrane CD39 expression via endocytosis in bone marrow-derived dendritic cells (BMDCs), which was positively associated with decreased enzymatic activity in ATP metabolism and increased eATP accumulation, leading to the activation of P2X7R, which mediated a pro-inflammatory effect ${ }^{[80]}$.

\section{CD39 and macrophage cells}

Anna et al. defined macrophage extracellular purine metabolism as a novel checkpoint in macrophage cell fate decision-making and an attractive target to control pathological macrophages in immune-mediated diseases ${ }^{[81]}$. The expression of CD39 and CD73 in M2 macrophages was significantly higher than in proinflammatory M1 macrophages ${ }^{[82]}$. By regulating the concentration of purine in the extracellular space, the CD39/CD73 system helps fine-tune the differentiation and activity of macrophages. Moreover, the lack of CD39 can lead to the accumulation of ATP, which stimulates macrophages to release pro-inflammatory cytokines ${ }^{[83,84]}$. Depletion of ATP by soluble CD39-like apyrase suppressed macrophage phagocytosis in vitro $^{[85]}$. In the presence of exogenously added ATP, TLR-stimulated macrophages hydrolyze ATP via CD39 to regulate their own activation state, and the loss of CD39 expression blocks the regulatory development of macrophages and leads to fatal inflammatory responses and septic shock in mice ${ }^{[86]}$. Luiz et al. found that CD39-/- macrophages stimulated with LPS and ATP exhibit increased nuclear factor-kB activation and IL-1 $\beta$ production ${ }^{[87]}$. In another study, blocking the expression of CD39 on the surface of macrophages enhanced the production of TNF- $\alpha$ and IL-12 significantly but decreased the production of IL-10 ${ }^{[87,88]}$.

ATP-based intercellular communication is mediated by P2X4R and P2X7R, and is a feature of proinflammatory macrophages. It was shown that CD39-expressing macrophages played a role in modulating the P2X7R-dependent production of IL-1 $\beta$ [89]. A previous report demonstrated that P2X7R activation triggers the initiation of lipid raft-dependent regulatory pathways that up-regulate CD39 activity. This mechanism could limit macrophage responses in inflammation, hence, restoring homeostasis ${ }^{[90]}$. A different study showed that cAMP up-regulates the transcription of CD39 in mouse macrophages, which is dependent on protein kinase A (PKA), phosphoinositide 3-kinase (PI3K), and extracellular signal-regulated kinase $(\mathrm{ERK})^{[91]}$. 
Tumor associated macrophages (TAMs) are an important component of the tumor microenvironment. In some cancers, TAMs can form up to $50 \%$ of tumor tissue and seriously impair anti-tumor immunity ${ }^{[22]}$. It has been shown that macrophages were reduced in the lungs of tumor-bearing mice treated with anti-CD39[73]. Co-culture of healthy donor monocytes with ovarian cancer cells induced the differentiation of monocytes into anti-inflammatory M2 macrophages expressing high levels of CD73 and CD39. These ADO-producing TAMs were further demonstrated to inhibit $\mathrm{CD} 4^{+}$T-cell activation in vitro ${ }^{[92]}$.

\section{CD39 and endothelial cells}

Endothelial cells and related vascular smooth muscle cells express CD39, which plays a key role in inflammation and thrombus reduction ${ }^{[93]}$. CD39 expressed by vascular endothelial cells could limit excessive polymorphonuclear leukocyte infiltration by providing increased ADO concentrations at hypoxic and inflammation sites ${ }^{[60]}$. The arterial expression and functionality of CD39 is decreased in hypertension. The reduced ectonucleotidase activity of CD39 may enhance pathology-associated vascular damage, increase endothelial permeability and inflammation, and increase the risk of end-organ damage and thrombogenesis ${ }^{[94]}$. In tumor environment, the expression of CD39 in vascular system, especially endothelial cells, can promote tumor growth by scavenging eATP ${ }^{[95]}$. The endothelial CD39/CD73 axis regulates hemostasis by transforming the local environment from a prethrombotic state rich in ATP and ADP into an antithrombotic environment rich in $\mathrm{ADO}^{[96-98]}$. CD39 plays the role of an endothelial thromboregulator by demonstrating that CD39transfected COS cells acquire the ability to inhibit ADP-induced aggregation in platelet-rich plasma ${ }^{\text {99-101] }}$. Next to inhibition of platelet activation, the local release of CD39 mRNA in atherosclerotic blood vessels supports the integrity of the endothelium and inhibits extracellular nucleotide-induced smooth muscle cell proliferation $^{[102]}$. Paradoxically, Aho et al. showed that elevated eATP or inhibition of CD39 activity has a protective effect against DNA damage in endothelial cells ${ }^{[103]}$. However, this effect could not be replicated in cancer cells.

\section{CD39 and platelets}

Platelets are known to express both CD39 and CD73 on their surface ${ }^{[04]}$. CD39 rapidly and preferentially metabolizes ATP and ADP released from activated platelets into AMP, thereby drastically reducing or even abolishing platelet aggregation and recruitment ${ }^{[105]}$. Unlike P2Y12R inhibitors and GPIIb/IIIa blockers, CD39 does not directly interfere with platelets; instead, it clears ADP around the platelets and maintains platelet functions ${ }^{[106]}$. A recombinant soluble form of human CD39 strongly inhibits human platelet aggregation induced by agonists ${ }^{[107-109]}$. Mice over-expressing human CD39 are resistant to arterial thrombosis induced by oxidative damage, which may be due to the decreased activation of platelet fibrinogen receptor $\alpha \mathrm{IIb} / \beta 3^{[110]}$. CD39-null mice manifest an increase in circulating platelet-leukocyte heteroaggregates, which suggests the presence of heterotypic crosstalk between the coagulation process and inflammatory systems [111]. The expression of CD39 and CD73 increases significantly on the platelet surface upon stimulation with thrombin, which indicates a thrombin-mediated externalization of these ectonucleotidases ${ }^{[12]}$. Although CD39 has been considered an important inhibitor of platelet activation, Enjyoji et al. reported that CD39 knockout paradoxically leads to disordered hemostasis, and they speculate there is a dual role for adenosine triphosphate diphosphohydrolase in modulating hemostasis and thrombotic reactions. ${ }^{[13]}$.

\section{CD39 and extracellular vesicles (EVs)}

Cell membrane-expressed E-NTPDases include CD39 are also found in circulating microparticles in human plasma ${ }^{[114]}$. Tumor-derived EVs, including exosomes, microvesicles, and apoptotic bodies, have been shown to inhibit anti-tumor T-cells through CD39, CD73, and ADO signaling pathways ${ }^{[115,116]}$. Zhang et al. showed that CD19+ EVs from B cells hydrolyzed ATP from chemotherapy-treated tumor cells into ADO via CD39 and CD73 vesicle-incorporated proteins, thus impairing CD8 ${ }^{+}$T-cell responses ${ }^{[117]}$. In microenvironments containing $\mathrm{CD} 39^{+} \mathrm{CD} 73^{+}$exosomes, CD73 is readily available to $\mathrm{CD} 4{ }^{+} \mathrm{CD} 39^{+} \mathrm{CD} 73^{\text {neg }}$ Tregs for the production of immunosuppressive $\mathrm{ADO}^{[118]}$. Increased plasma microparticles (MP) expressing CD39 were observed in patients with liver injury, and plasma CD133 MP levels increased in a CD39-dependent manner during experimental acute liver injury ${ }^{[119]}$. CD $4^{+}$T-cell-derived CD $161^{+} \mathrm{CD} 39^{+}$and $\mathrm{CD} 39^{+} \mathrm{CD} 73^{+}$ 
MPs contain pro-inflammatory and anti-inflammatory information, respectively, and could serve as new biomarkers for diseases, such as rheumatoid arthritis ${ }^{[120]}$. Angioni et al. demonstrated that in response to pro-inflammatory cytokines, bone marrow mesenchymal stromal cells produce EVs that are enriched in TIMP-1,CD39, and CD73, which inhibit angiogenesis by targeting both extracellular matrix remodeling and endothelial cell migration ${ }^{[121]}$. Furthermore, CD39 expressed in EVs derived from endothelial cells influences thrombus progression ${ }^{[23,122]}$.

\section{The functions of CD39 in immune-related diseases}

\section{CD39 and sepsis}

Sepsis is caused by an imbalance in the host immune response to infection, and it can lead to life-threatening organ dysfunction. CD39 attenuates sepsis-associated liver injury by scavenging eATP and ultimately generating ADO. Boosting of CD39 can suppress P2X7R response and trigger adenosinergic signaling to limit systemic inflammation and restore liver homeostasis during the acute phase of sepsis ${ }^{[87]}$. CD39 enhancement also exhibited an enhancing effect on the ability of renal tubular epithelial cells to resist LPS-induced damage, improve cell viability and apoptosis, and inhibit NLRP3 inflammasome activation ${ }^{[123]}$. Increase $\mathrm{CD}^{+} 9^{+}$Tregs was associated with a poor prognosis for sepsis patients, which suggests that the CD39+ Treg level is a potential biomarker for predicting the outcome of sepsis in patients ${ }^{[124]}$. CD39 affects the pro-inflammatory response of sepsis mediated by immune cells and endothelial cells. Cohen et al. showed that TLR-stimulated macrophages modulate their activation state by increasing the synthesis and secretion of $\mathrm{ATP}^{[86]}$. Macrophages lacking CD39 are unable to transition to a regulatory state and consequently continue to produce inflammatory cytokines. Furthermore, the macrophage-specific expression of CD39 is critical for preventing lethal hyperinflammatory responses to LPS in vivo ${ }^{[86]}$. Overexpression of CD39 in the endothelium efficiently abrogated the initial phases of ATP secretion in response to LPS endotoxin and markedly inhibited IL- $1 \alpha$ release ${ }^{[125]}$. CD39 expression is up-regulated during sepsis ${ }^{[126,127]}$. Bao et al. indicate that $\mathrm{ADO}$, the $\mathrm{ADO} \mathrm{A}_{2} \mathrm{AR}$ agonist, $\mathrm{E} 2 \mathrm{~F}-1$, and $\mathrm{CREB}$ are potential factors contributing to the increased expression of CD39 and CD73 on Treg cell surface during sepsis ${ }^{[128]}$. It was reported miR-155 induces an increased percentage of CD39+ Tregs and thus immunosuppression in sepsis patients ${ }^{[129]}$.

\section{CD39 and inflammatory bowel diseases (IBD)}

IBD, including Crohn's disease and ulcerative colitis, is characterized by chronic relapsing intestinal inflammation ${ }^{[130]}$. The expression of CD39 on endothelial cells or immune cells integrates the dynamic balance of immunity, thereby controlling hemostasis and immunobiological responses, which appear disrupted in IBD ${ }^{[131]}$. Decreased abundance of CD39-expressing intraepithelial T-cells is common in IBD patients ${ }^{[132]}$. CD39 expression by Treg was lower in active inflammatory bowel disease and increased significantly after treatment in responders ${ }^{[133]}$. Single nucleotide polymorphisms (SNPs) adjacent to the CD39 promoter region have been associated with low levels of CD39 mRNA expression which confer susceptibility to Crohn's disease ${ }^{[131]}$. The number of SupTh17 cells is diminished in Crohn's disease patients; however, they express higher levels of CD39 and effectively generate eAMP and ADO and, hence, can potently suppress effector T-cell responses via $\mathrm{A}_{2 \mathrm{~A}} \mathrm{R}{ }^{[134]}$. In the mouse model, changes in ADO production, such as those associated with CD39 or CD73 gene deletions, lead to a more severe course of experimental colitis ${ }^{[131,135]}$. Paradoxically, Kunzli et al. ${ }^{[136]}$ found that 2,4,6-trinitrobenzene sulphonic acid colitis was attenuated in CD39-null mice, and impaired adaptive cellular immune reactivity of CD39-null environment appears protective in hapten-mediated Th1-type colitis.

\section{CD39 and ischemia-reperfusion injury (IRI)}

In CD39 and CD73 knockout mice, organ damage and inflammation caused by ischemia in the brain ${ }^{84]}$, heart ${ }^{[137-139]}$, kidney ${ }^{[140,141]}$, liver ${ }^{[142,143]}$, intestine ${ }^{[144,145]}$ and hindlimb ${ }^{[146]}$ were more severe than those in the corresponding wild-type mice. Studies have shown that boosting of CD39 can reduce organ damage caused by IR ${ }^{[147-150]}$. The protective effect observed in CD39 over-expressing mice on myocardial ischemia has been shown to work through the $\mathrm{A}_{2 \mathrm{~B}} \mathrm{R}$ dependence mechanism [151]. This protective effect was also observed in pigs over-expressing CD39 ${ }^{[152]}$. A variety of immune cells are involved in the protective effect 
of CD39 on IRI. In vitro activated Tregs ameliorated IRI through a CD39-dependent mechanism ${ }^{[153]}$. In addition, deletion of CD39 in NK cells inhibits their activation and protects partial hepatic IRI by diminishing IFN- $\gamma$ production ${ }^{[67]}$.IRI is inherent in organ transplantation and has an impact on both short-term and longterm outcomes of the transplantation. CD39 expression in mouse liver conventional myeloid DCs (mDCs) limits the pro-inflammatory activity of $\mathrm{mDCs}$ and provides protection against the innate immune response against liver transplant IRI ${ }^{[78]}$. Furthermore, liver grafts from CD39-over-expressing mice have been shown to be protected from IRI due to the reduced numbers of resident CD4 ${ }^{+}$T-cells ${ }^{[154]}$. The expression of CD39 can be up-regulated by hypoxia and specificity protein 1 (Sp1)-mediated induction of cardiac CD39 during myocardial ischemia ${ }^{[24]}$.

\section{CD39 and allergic diseases}

CD39 expressed in Tregs is involved in a variety of allergic diseases. Tregs can suppress contact hypersensitivity reactions through a CD39, adenosine-dependent mechanism by blocking leukocyte adhesion to endothelium ${ }^{[155]}$. Tregs remove eATP by CD39 and, therefore, abrogate the shedding of CD62L, leading to defective sensitization in contact hypersensitivity reactions ${ }^{[156]}$. CD39 mediates the protective role of $\mathrm{CD} 4^{+}$Foxp $^{+}{ }^{+}$Tregs in allergic airway inflammation by regulating ATP and ADO levels ${ }^{[157]}$. In allergic asthma, increased Tc2 and Tc17 may be related to insufficient CD39 ${ }^{+}$Tregs $^{[158]}$. Wang et al. found that the plasticity of Tregs transforming into IL- $17^{+}$Foxp $3^{+} \mathrm{CD} 4^{+} \mathrm{T}$-cells, the reduced frequency of CD $39^{+}$Tregs, and the less effective suppression of IL-17 produced by residual CD39+ Tregs leads to an imbalance of Th17 and Tregs in asthma ${ }^{[159]}$. CD39 expression was down-regulated in allergic asthma and was positively correlated with serum IL-4, IL-17A, and GATA3 expression and negatively correlated with serum TGF- $\beta$ and Foxp3 expression ${ }^{[160]}$. CD39 deficient DCs exhibit limited capacity to induce Th2 immunity in a DC-driven model of allergic airway inflammation in vivo ${ }^{[161]}$. Li et al. demonstrated that a reduction in CD39 expression may be associated with the development of allergic airway inflammation and that apyrase alleviates airway inflammation by decreasing the chemotactic migration of DCs towards eATP ${ }^{[162]}$.

\section{CD39 and SLE}

SLE patients exhibit increased levels of ATP which binds to P2XR resulting in activation of the inflammasome and consequent release of cytokines associated with disease pathogenesis ${ }^{[163]}$. CD39 expression in lymphocytes was increased in SLE patients, suggesting a compensatory mechanism to help control inflammation [164]. However, Loza et al. showed decreased CD39 expression in Tregs from SLE patients, demonstrating a defect restricted to this subset of cells ${ }^{[165]}$.

\section{CD39 and diabetes}

Children diagnosed with type 1 diabetes (T1D) show signs of low CD39 ${ }^{+} / \mathrm{CD}_{4} 4 \mathrm{RA}^{+}$Treg cells, which may indicate loss of its suppressive function ${ }^{[166]}$. Lower expression of CD39 in memory Tregs has been reported as a potential mechanism explaining the defective suppressive function of Tregs in T1D patients ${ }^{[167]}$. The percentages of $\mathrm{CD} 39^{+}$and $\mathrm{CD} 39^{+} \mathrm{CD} 19^{+}$cells were associated with glycated hemoglobin and fasting plasma glucose levels. $\mathrm{CD} 39^{+}$cells might have a balancing regulatory role in the inflammatory process observed in patients with type 2 diabetes (T2D) ${ }^{[168]}$. The T2D patients with obesity showed significantly lower percentages of CD39+ Treg cells and a negative correlation between CD39 ${ }^{+}$Treg cells and weight, and body mass index was detected ${ }^{[169]}$. Mesenchymal stem cells from human gingiva can migrate to the pancreas and local lymph nodes and act through the CD39/CD73 pathway to regulate effector T-cells. Infusion of GMSCs significantly controlled blood glucose levels, delayed diabetes onset, and ameliorated pathology scores in pancreas ${ }^{[170]}$. CD39 KO mice developed diabetes more rapidly and with higher frequency than WT mice, while CD39 overexpressing mice were protected. Furthermore, adoptive transfer experiments indicated that tissue-restricted overexpression of CD39 conferred robust protection, suggesting that this may be a useful strategy to protect islet grafts from T cell-mediated injury ${ }^{[171]}$.

\section{CD39 and tumor}

CD39 is expressed in tumor cells and tumor-infiltrating immune cells and affects tumor development in vari- 
ous interrelated ways. CD39 is up-regulated in a variety of human cancers, such as leukemia and head, neck, colorectal, liver, and gastric cancers, and the expression level of CD39 is often related to the stage and severity of a disease ${ }^{[172-178]}$. CD39 is highly expressed on tumor-infiltrating immune cells, particularly effector T-cells and Tregs. CD39 has been shown to be highly expressed in tumor-infiltrating CD8 ${ }^{+}$T-cells in a variety of human tumors, including renal cell carcinoma, gastric cancer ${ }^{[39]}$, lung cancer, colorectal cancer, breast cancer ${ }^{[40]}$ and head and neck cancer ${ }^{[41]}$. Tumor-infiltrating CD $39^{\text {high }} \mathrm{CD} 8^{+}$T-cells increase with tumor growth, and exhibit features of exhaustion, including decreased TNF, IL-2, and IFN- $\gamma$ production as well as increased expression of many inhibitory/checkpoint receptors, such as programmed cell death 1 , $\mathrm{T}$ cell immunoglobulin and mucin-do-main-containing molecule 3, Lymphocyte-activation gene 3, T cell immunoglobulin and ITIM domain, and 2B4 [40]. Tregs mediate immunosuppression through several mechanisms, including CD39dependent production of ADO. Transcriptional profiling of Tregs revealed a substantial number of candidate genes with the potential to mediate suppression, including the highly expressed CD39 ${ }^{[36]}$. CD39 was found expressed in CD8 ${ }^{+}$Tregs, and CD39 expression correlated with suppression activity mediated by CD $8^{+}$Tregs ${ }^{[179]}$. Hu et al. identified a novel CD39 ${ }^{+} \gamma \delta$ Treg in human colorectal cancer patients ${ }^{[35]}$. Furthermore, the $\mathrm{CD} 39^{+} \gamma \delta$ Tregs are the predominant regulatory T-cells observed in colorectal cancer patients, with a more potent immunosuppressive activity than $\mathrm{CD} 4^{+}$or $\mathrm{CD} 8^{+}$Tregs, and acting through the ADO-mediated pathway ${ }^{[35]}$. Tumor-infiltrating CD39+ Tregs accumulate in colon tumors and exhibit high expression of surface molecules related to immunosuppression, such as inducible co-stimulator, programmed cell death protein ligand 1, and cytotoxic T lymphocyte associated antigen 4. CD39+ Tregs also show potent suppressive capacity on proliferation and IFN- $\gamma$ secretion by conventional T-cells ${ }^{[37]}$. In patients with colon cancer, circulating Tregs express high levels of CD39, which contributes to the reduced transendothelial migration of effector T-cells into tumors ${ }^{[180]}$. Lower baseline levels of circulating Tregs $\left(\mathrm{CD} 4{ }^{+} \mathrm{CD} 25^{\text {high }} \mathrm{CD} 39^{+}\right)$in melanoma patients were associated with better relapse-free survival ${ }^{[181]}$. There are few studies on the role of CD39 in anti-tumor immunity mediated by NK cells. Zhang et al. found that CD39 was expressed in tumor-infiltrating NK cells. Furthermore, POM-1 suppressed experimental and spontaneous metastases in four tumor models, and its anti-metastatic activity was completely abrogated in NK-cell-depleted mice [72]. The proportion of NK cells significantly decreased, but CD39 was obviously up-regulated in NK cells from cancerous tissues compared to paired peripheral blood in esophageal squamous cell carcinoma patients. Furthermore, tumor-infiltrating CD $39^{+}$NK cells exhibited a phenotype of functional impairment and were correlated with poor prognosis ${ }^{[182]}$. Myeloid-derived suppressor cells (MDSCs) have been recognized as one of major contributors to tumor-induced immunosuppression ${ }^{[183]}$. MDSCs in peripheral blood and tumor tissues from patients with non-small cell lung cancer were shown to express CD39. Tumor TGF- $\beta$ stimulated CD39 and CD73 expression in MDSCs, thereby inhibited T cell and NK cell activity, and protected tumor cells from the cytotoxic effect of chemotherapy through ectonucleotidase activity ${ }^{[184]}$. Compared to other myeloid cells present in the blood of patients with colorectal cancer, gMDSCs that expressed high levels of PD-L1, CD39, and CD73 exerted a robust immunosuppressive activity, ${ }^{[185]}$. Metformin treatment blocks the suppressive function of MDSCs in patients with ovarian cancer by down-regulating the expression and ectoenzymatic activity of CD39 and CD73 on monocytic and polymononuclear MDSC subsets ${ }^{[186]}$. In addition, the growth of multiple syngeneic tumors is reduced in global CD39 gene-targeted mice [95, 187, 188]. Similarly, CD39-deficient mice are resistant to the formation of metastasis in models of disseminated disease or spontaneous metastasis ${ }^{[2,189]}$. In a dissemination liver metastasis model, MC-26 cell line-derived hepatic metastases grew significantly faster in CD39 over-expressing transgenic mice when compared to those in CD39-deficient mice ${ }^{[190]}$. Additionally, pharmacological blockade of CD39 activity with an antagonistic antibody or the inhibitor POM-1 was shown to significantly limit tumor growth and improve anti-tumor immunity $[187,189,191,192]$.

\section{Perspectives}

CD39 has correlation to various immune cells and plays vital roles in multiple physiological and pathological processes. In particular, CD39 is considered to be a new marker of T-cell exhaustion and an immune checkpoint target for cancer treatment. Targeting of both the A2aR and CD73 has been shown to be efficacious in preclinical cancer models. However, unlike treatment targeting the downstream production or 
function of $\mathrm{ADO}$, inhibition of CD39 not only limits the production of ADO, but also prevents the degradation of eATP. So CD39 is uniquely positioned in ATP-adenosine axis. Monoclonal antibodies targeting CD39 have been developed and were demonstrated to significantly reduce tumor growth in preclinical cancer models, including as single agent ${ }^{[64]}$. Furthermore, targeting CD39 in combination with other anticancer strategies, including immunotherapies, and chemotherapy is another promising combination. It was shown recently that anti-CD39 turns "cold" anti-PD1 resistant tumors "hot" and sensitive ${ }^{[192]}$, so the combination therapy of CD39 and PD-1 is expected. However, not all extracellular ADO was inhibited by anti-CD39, and other adenosine production pathways may also be involved in this process. Actually, AMP can be also obtained through the transformation of $\mathrm{NAD}^{+}$by CD38 and CD203a ${ }^{[9-12]}$. So combination therapy targeting multiple adenosine-generating enzymes may be more effective. Furthermore, CD39 has vast therapeutic potential in a wide variety of disorders. However, considering the extensive physiological effects of eATP and ADO and the opposite effect of CD39 in some diseases, therapy targeting CD39 requires more in-depth research and individualized treatment.

\section{Acknowledgments}

The authors are indebted to all the donors whose names were not included in the author list, but who participated in our study.

\section{Funding}

This work was supported by Doctoral Startup Fund of Jining Medical University (NO. 2017JYQD24), Research Fund for Lin He's Academician Workstation of New Medicine and Clinical Translation in Jining Medical University (NO. JYHL2018MS11), Chinese and foreign cooperation cultivation project of Jining medical university, National Natural Science Foundation of China (No. 81874169, 81771668).

\section{Competing interests}

The authors declare no potential conflicts of interest.

\section{References}

1. Di Virgilio F, Boeynaems JM, Robson SC. Extracellular nucleotides as negative modulators of immunity. Curr Opin Pharmacol 2009; 9:507-13.

2. Burnstock G, Knight GE. Cellular distribution and functions of P2 receptor subtypes in different systems. Int Rev Cytol 2004; 240:31-304.

3. Pelleg A, Schulman ES, Barnes PJ. Adenosine 5'-triphosphate's role in bradycardia and syncope associated with pulmonary embolism. Respir Res 2018; 19:142.

4. Burnstock G. Purinergic signaling and vascular cell proliferation and death. Arterioscler Thromb Vasc Biol 2002; 22:364-73.

5. Chen Y, Corriden R, Inoue Y, et al. ATP release guides neutrophil chemotaxis via P2Y2 and A3 receptors. Science 2006; 314:1792-5.

6. Kronlage M, Song J, Sorokin L, et al. Autocrine purinergic receptor signaling is essential for macrophage chemotaxis. Sci Signal 2010; 3:ra55.

7. Axtell RA, Sandborg RR, Smolen JE, et al. Exposure of human neutrophils to exogenous nucleotides causes elevation in intracellular calcium, transmembrane calcium fluxes, and an alteration of a cytosolic factor resulting in enhanced superoxide production in response to FMLP and arachidonic acid. Blood 1990; 75:1324-32.

8. Iwata M, Ota KT, Li XY, et al. Psychological Stress Activates the Inflammasome via Release of Adenosine Triphosphate and Stimulation of the Purinergic Type 2X7 Receptor. Biol Psychiatry 2016; 80:12-22. 
9. Horenstein AL, Chillemi A, Zaccarello G, et al. A CD38/CD203a/CD73 ectoenzymatic pathway independent of CD39 drives a novel adenosinergic loop in human T lymphocytes. Oncoimmunology 2013; $2: \mathrm{e} 26246$.

10. Horenstein AL, Chillemi A, Quarona V, et al. NAD(+)-Metabolizing Ectoenzymes in Remodeling Tumor-Host Interactions: The Human Myeloma Model. Cells 2015; 4:520-37.

11. Chen L, Diao L, Yang Y, et al. CD38-Mediated Immunosuppression as a Mechanism of Tumor Cell Escape from PD-1/PD-L1 Blockade. Cancer Discov 2018; 8:1156-1175.

12. Vaisitti T, Audrito V, Serra S, et al. NAD+-metabolizing ecto-enzymes shape tumor-host interactions: the chronic lymphocytic leukemia model. FEBS Lett 2011; 585:1514-20.

13. Fredholm BB, AP IJ, Jacobson KA, et al. International Union of Basic and Clinical Pharmacology. LXXXI. Nomenclature and classification of adenosine receptors-an update. Pharmacol Rev 2011; 63:1-34.

14. Vijayan D, Young A, Teng MWL, Smyth MJ. Targeting immunosuppressive adenosine in cancer. Nat Rev Cancer 2017; 17:709-724.

15. Jacobson KA, Gao Z-G. Adenosine receptors as therapeutic targets. Nature reviews. Drug discovery $2006 ; 5: 247-264$.

16. Cronstein BN, Levin RI, Philips M, et al. Neutrophil adherence to endothelium is enhanced via adenosine A1 receptors and inhibited via adenosine A2 receptors. J Immunol 1992; 148:2201-6.

17. Vecchio EA, Tan CY, Gregory KJ, et al. Ligand-Independent Adenosine A2B Receptor Constitutive Activity as a Promoter of Prostate Cancer Cell Proliferation. J Pharmacol Exp Ther 2016; 357:36-44.

18. Ohta A, Gorelik E, Prasad SJ, et al. A2A adenosine receptor protects tumors from antitumor T cells. Proc Natl Acad Sci U S A 2006; 103:13132-7.

19. Allard B, Beavis PA, Darcy PK, Stagg J. Immunosuppressive activities of adenosine in cancer. Curr Opin Pharmacol 2016; 29:7-16.

20. Stockwell J, Jakova E, Cayabyab FS. Adenosine A1 and A2A Receptors in the Brain: Current Research and Their Role in Neurodegeneration. Molecules 2017; 22.

21. Beavis PA, Stagg J, Darcy PK, Smyth MJ. CD73: a potent suppressor of antitumor immune responses. Trends Immunol 2012; 33:231-7.

22. Regateiro FS, Howie D, Nolan KF, et al. Generation of anti-inflammatory adenosine by leukocytes is regulated by TGF-beta. Eur J Immunol 2011; 41:2955-65.

23. Deaglio S, Robson SC. Ectonucleotidases as regulators of purinergic signaling in thrombosis, inflammation, and immunity. Adv Pharmacol 2011; 61:301-32.

24. Eltzschig HK, Kohler D, Eckle T, et al. Central role of Sp1-regulated CD39 in hypoxia/ischemia protection. Blood 2009; 113:224-32.

25. Dwyer KM, Hanidziar D, Putheti P, et al. Expression of CD39 by human peripheral blood CD4+ CD25+ T cells denotes a regulatory memory phenotype. Am J Transplant 2010; 10:2410-20.

26. Fang F, Yu M, Cavanagh MM, et al. Expression of CD39 on Activated T Cells Impairs their Survival in Older Individuals. Cell Rep 2016; 14:1218-1231.

27. Deaglio S, Dwyer KM, Gao W, et al. Adenosine generation catalyzed by CD39 and CD73 expressed on regulatory T cells mediates immune suppression. J Exp Med 2007; 204:1257-65.

28. Mascanfroni ID, Takenaka MC, Yeste A, et al. Metabolic control of type 1 regulatory T cell differentiation by AHR and HIF1- $\alpha$. Nature Medicine 2015; 21. 
29. Mandapathil M, Lang S, Gorelik E, Whiteside TL. Isolation of functional human regulatory T cells (Treg) from the peripheral blood based on the CD39 expression. J Immunol Methods 2009; 346:55-63.

30. Ye L, Goodall JC, Zhang L, et al. TCR usage, gene expression and function of two distinct FOXP3(+)Treg subsets within CD4(+)CD25(hi) T cells identified by expression of CD39 and CD45RO. Immunol Cell Biol 2016; 94:293-305.

31. Lu Y, Wang X, Gu J, et al. iTreg induced from CD39(+) naive T cells demonstrate enhanced proliferate and suppressive ability. Int Immunopharmacol 2015; 28:925-30.

32. Zhang X, Ouyang X, Xu Z, et al. CD8+CD103+ iTregs Inhibit Chronic Graft-versus-Host Disease with Lupus Nephritis by the Increased Expression of CD39. Mol Ther 2019; 27:1963-1973.

33. Gu J, Ni X, Pan X, et al. Human CD39(hi) regulatory T cells present stronger stability and function under inflammatory conditions. Cell Mol Immunol 2017; 14:521-528.

34. Borsellino G, Kleinewietfeld M, Di Mitri D, et al. Expression of ectonucleotidase CD39 by Foxp3+ Treg cells: hydrolysis of extracellular ATP and immune suppression. Blood 2007; 110:1225-32.

35. Hu G, Wu P, Pu C, et al. Tumor-infiltrating CD39+ үôTregs are novel immunosuppressive T cells in human colorectal cancer. Oncoimmunology 2017; 6:-.

36. Plitas G, Rudensky AY. Regulatory T Cells: Differentiation and Function. Cancer Immunol Res 2016; 4:721-5.

37. Ahlmanner F, Sundström P, Akeus P, et al. CD39(+) regulatory T cells accumulate in colon adenocarcinomas and display markers of increased suppressive function. Oncotarget 2018; 9:36993-37007.

38. Zhou Q, Yan J, Putheti P, et al. Isolated CD39 expression on CD4+ T cells denotes both regulatory and memory populations. Am J Transplant 2009; 9:2303-11.

39. Thelen M, Lechner A, Wennhold K, et al. CD39 Expression Defines Cell Exhaustion in Tumor-Infiltrating CD8(+) T Cells-Letter. Cancer Res 2018; 78:5173-5174.

40. Canale FP, Ramello MC, Nunez N, et al. CD39 Expression Defines Cell Exhaustion in Tumor-Infiltrating CD8(+) T Cells. Cancer Res 2018; 78:115-128.

41. Duhen T, Duhen R, Montler R, et al. Co-expression of CD39 and CD103 identifies tumor-reactive CD8 T cells in human solid tumors. Nat Commun 2018; 9:2724.

42. Bai A, Moss A, Rothweiler S, et al. NADH oxidase-dependent CD39 expression by CD8(+) T cells modulates interferon gamma responses via generation of adenosine. Nat Commun 2015; 6:8819.

43. Bai A, Robson S. Beyond ecto-nucleotidase: CD39 defines human Th17 cells with CD161. Purinergic Signal 2015; 11:317-9.

44. Chalmin F, Mignot G, Bruchard M, et al. Stat3 and Gfi-1 transcription factors control Th17 cell immunosuppressive activity via the regulation of ectonucleotidase expression. Immunity 2012; 36:362-73.

45. Fernandez D, Flores-Santibanez F, Neira J, et al. Purinergic Signaling as a Regulator of Th17 Cell Plasticity. PLoS One 2016; 11:e0157889.

46. Liberal R, Grant CR, Ma Y, et al. CD39 mediated regulation of Th17-cell effector function is impaired in juvenile autoimmune liver disease. J Autoimmun 2016; 72:102-12.

47. Lin R, Zhang H, Yuan Y, et al. Fatty Acid Oxidation Controls CD8(+) Tissue-Resident Memory T-cell Survival in Gastric Adenocarcinoma. Cancer Immunol Res 2020; 8:479-492.

48. Otsuka A, Hanakawa S, Miyachi Y, Kabashima K. CD39: a new surface marker of mouse regulatory $\gamma \delta$ T cells. J Allergy Clin Immunol 2013; 132:1448-51. 
49. Kaku H, Cheng KF, Al-Abed Y, Rothstein TL. A novel mechanism of B cell-mediated immune suppression through CD73 expression and adenosine production. J Immunol 2014; 193:5904-13.

50. Figueiro F, Muller L, Funk S, et al. Phenotypic and functional characteristics of CD39(high) human regulatory B cells (Breg). Oncoimmunology 2016; 5:e1082703.

51. Saze Z, Schuler PJ, Hong CS, et al. Adenosine production by human B cells and B cell-mediated suppression of activated T cells. Blood 2013; 122:9-18.

52. Dwyer KM, Deaglio S, Gao W, et al. CD39 and control of cellular immune responses. Purinergic Signal 2007; 3:171-80.

53. Jacob F, Perez Novo C, Bachert C, Van Crombruggen K. Purinergic signaling in inflammatory cells: P2 receptor expression, functional effects, and modulation of inflammatory responses. Purinergic Signal 2013; 9:285-306.

54. Przybyla T, Sakowicz-Burkiewicz M, Pawelczyk T. Purinergic signaling in B cells. Acta Biochim Pol 2018; 65:1-7.

55. Sakowicz-Burkiewicz M, Kocbuch K, Grden M, et al. High glucose concentration impairs ATP outflow and immunoglobulin production by human peripheral B lymphocytes: involvement of P2X7 receptor. Immunobiology 2013; 218:591-601.

56. Pulte ED, Broekman MJ, Olson KE, et al. CD39/NTPDase-1 activity and expression in normal leukocytes. Thromb Res 2007; 121:309-17.

57. Flogel U, Burghoff S, van Lent PL, et al. Selective activation of adenosine A2A receptors on immune cells by a CD73-dependent prodrug suppresses joint inflammation in experimental rheumatoid arthritis. Sci Transl Med 2012; 4:146ra108.

58. Barletta KE, Ley K, Mehrad B. Regulation of neutrophil function by adenosine. Arterioscler Thromb Vasc Biol 2012; 32:856-64.

59. Eltzschig HK, Eckle T, Mager A, et al. ATP release from activated neutrophils occurs via connexin 43 and modulates adenosine-dependent endothelial cell function. Circ Res 2006; 99:1100-8.

60. Eltzschig HK, Thompson LF, Karhausen J, et al. Endogenous adenosine produced during hypoxia attenuates neutrophil accumulation: coordination by extracellular nucleotide metabolism. Blood 2004; 104:398692.

61. Corriden R, Chen Y, Inoue Y, et al. Ecto-nucleoside triphosphate diphosphohydrolase 1 (ENTPDase1/CD39) regulates neutrophil chemotaxis by hydrolyzing released ATP to adenosine. J Biol Chem 2008; 283:28480-6.

62. Eltzschig HK, Weissmuller T, Mager A, Eckle T. Nucleotide metabolism and cell-cell interactions. Methods Mol Biol 2006; 341:73-87.

63. Shah D, Romero F, Stafstrom W, et al. Extracellular ATP mediates the late phase of neutrophil recruitment to the lung in murine models of acute lung injury. Am J Physiol Lung Cell Mol Physiol 2014; 306:L152-61.

64. Allard D, Allard B, Stagg J. On the mechanism of anti-CD39 immune checkpoint therapy. J Immunother Cancer 2020; 8.

65. Inoue Y, Chen Y, Hirsh MI, et al. A3 and P2Y2 receptors control the recruitment of neutrophils to the lungs in a mouse model of sepsis. Shock 2008; 30:173-7.

66. Reutershan J, Vollmer I, Stark S, et al. Adenosine and inflammation: CD39 and CD73 are critical mediators in LPS-induced PMN trafficking into the lungs. FASEB J 2009; 23:473-82. 
67. Beldi G, Banz Y, Kroemer A, et al. Deletion of CD39 on natural killer cells attenuates hepatic ischemia/reperfusion injury in mice. Hepatology 2010; 51:1702-11.

68. Morandi F, Horenstein AL, Chillemi A, et al. CD56brightCD16- NK Cells Produce Adenosine through a CD38-Mediated Pathway and Act as Regulatory Cells Inhibiting Autologous CD4+ T Cell Proliferation. J Immunol 2015; 195:965-72.

69. Beldi G, Wu Y, Banz Y, et al. Natural killer T cell dysfunction in CD39-null mice protects against concanavalin A-induced hepatitis. Hepatology 2008; 48:841-52.

70. Nowak-Machen M, Schmelzle M, Hanidziar D, et al. Pulmonary natural killer T cells play an essential role in mediating hyperoxic acute lung injury. Am J Respir Cell Mol Biol 2013; 48:601-9.

71. Seshadri A, Brat GA, Yorkgitis BK, et al. Altered monocyte and NK cell phenotypes correlate with posttrauma infection. J Trauma Acute Care Surg 2019; 87:337-341.

72. Zhang H, Vijayan D, Li XY, et al. The role of NK cells and CD39 in the immunological control of tumor metastases. Oncoimmunology 2019; 8:e1593809.

73. Yan J, Li XY, Roman Aguilera A, et al. Control of Metastases via Myeloid CD39 and NK Cell Effector Function. Cancer Immunol Res 2020; 8:356-367.

74. Berchtold S, Ogilvie AL, Bogdan C, et al. Human monocyte derived dendritic cells express functional P2X and P2Y receptors as well as ecto-nucleotidases. FEBS Lett 1999; 458:424-8.

75. Mizumoto N, Kumamoto T, Robson SC, et al. CD39 is the dominant Langerhans cell-associated ectoNTPDase: modulatory roles in inflammation and immune responsiveness. Nat Med 2002; 8:358-65.

76. Cobbold SP, Adams E, Nolan KF, et al. Connecting the mechanisms of T-cell regulation: dendritic cells as the missing link. Immunol Rev 2010; 236:203-18.

77. Burch LH, Picher M. E-NTPDases in human airways: Regulation and relevance for chronic lung diseases. Purinergic Signal 2006; 2:399-408.

78. Yoshida O, Kimura S, Jackson EK, et al. CD39 expression by hepatic myeloid dendritic cells attenuates inflammation in liver transplant ischemia-reperfusion injury in mice. Hepatology 2013; 58:2163-75.

79. Mascanfroni ID, Yeste A, Vieira SM, et al. IL-27 acts on DCs to suppress the T cell response and autoimmunity by inducing expression of the immunoregulatory molecule CD39. Nat Immunol 2013; 14:105463.

80. Zhao R, Qiao J, Zhang X, et al. Toll-Like Receptor-Mediated Activation of CD39 Internalization in BMDCs Leads to Extracellular ATP Accumulation and Facilitates P2X7 Receptor Activation. Front Immunol 2019; 10:2524.

81. Ohradanova-Repic A, Machacek C, Charvet C, et al. Extracellular Purine Metabolism Is the Switchboard of Immunosuppressive Macrophages and a Novel Target to Treat Diseases With Macrophage Imbalances. Front Immunol 2018; 9:852.

82. Zanin RF, Braganhol E, Bergamin LS, et al. Differential macrophage activation alters the expression profile of NTPDase and ecto-5'-nucleotidase. PLoS One 2012; 7:e31205.

83. Hasko G, Csoka B, Koscso B, et al. Ecto-5'-nucleotidase (CD73) decreases mortality and organ injury in sepsis. J Immunol 2011; 187:4256-67.

84. Petrovic-Djergovic D, Hyman MC, Ray JJ, et al. Tissue-resident ecto-5' nucleotidase (CD73) regulates leukocyte trafficking in the ischemic brain. J Immunol 2012; 188:2387-98.

85. Feske S, Wulff H, Skolnik EY. Ion channels in innate and adaptive immunity. Annu Rev Immunol 2015; 33:291-353. 
86. Cohen HB, Briggs KT, Marino JP, et al. TLR stimulation initiates a CD39-based autoregulatory mechanism that limits macrophage inflammatory responses. Blood 2013; 122:1935-45.

87. Savio LEB, de Andrade Mello P, Figliuolo VR, et al. CD39 limits P2X7 receptor inflammatory signaling and attenuates sepsis-induced liver injury. J Hepatol 2017; 67:716-726.

88. Cohen HB, Ward A, Hamidzadeh K, et al. IFN-gamma Prevents Adenosine Receptor (A2bR) Upregulation To Sustain the Macrophage Activation Response. J Immunol 2015; 195:3828-37.

89. Levesque SA, Kukulski F, Enjyoji K, et al. NTPDase1 governs P2X7-dependent functions in murine macrophages. Eur J Immunol 2010; 40:1473-85.

90. Savio LEB, de Andrade Mello P, Santos S, et al. P2X7 receptor activation increases expression of caveolin-1 and formation of macrophage lipid rafts, thereby boosting CD39 activity. J Cell Sci 2020; 133.

91. Liao H, Hyman MC, Baek AE, et al. cAMP/CREB-mediated transcriptional regulation of ectonucleoside triphosphate diphosphohydrolase 1 (CD39) expression. J Biol Chem 2010; 285:14791-805.

92. Montalbán Del Barrio I, Penski C, Schlahsa L, et al. Adenosine-generating ovarian cancer cells attract myeloid cells which differentiate into adenosine-generating tumor associated macrophages - a self-amplifying, CD39- and CD73-dependent mechanism for tumor immune escape. J Immunother Cancer 2016; 4:49.

93. Kanthi YM, Sutton NR, Pinsky DJ. CD39: Interface between vascular thrombosis and inflammation. Curr Atheroscler Rep 2014; 16:425.

94. Roy C, Tabiasco J, Caillon A, et al. Loss of vascular expression of nucleoside triphosphate diphosphohydrolase-1/CD39 in hypertension. Purinergic Signal 2018; 14:73-82.

95. Feng L, Sun X, Csizmadia E, et al. Vascular CD39/ENTPD1 directly promotes tumor cell growth by scavenging extracellular adenosine triphosphate. Neoplasia 2011; 13:206-16.

96. Packham MA, Mustard JF. Platelet aggregation and adenosine diphosphate/adenosine triphosphate receptors: a historical perspective. Semin Thromb Hemost 2005; 31:129-38.

97. Atkinson B, Dwyer K, Enjyoji K, Robson SC. Ecto-nucleotidases of the CD39/NTPDase family modulate platelet activation and thrombus formation: Potential as therapeutic targets. Blood Cells Mol Dis 2006; $36: 217-22$.

98. Fung CY, Marcus AJ, Broekman MJ, Mahaut-Smith MP. P2X(1) receptor inhibition and soluble CD39 administration as novel approaches to widen the cardiovascular therapeutic window. Trends Cardiovasc Med 2009; 19:1-5.

99. Marcus AJ, Broekman MJ, Drosopoulos JH, et al. The endothelial cell ecto-ADPase responsible for inhibition of platelet function is CD39. J Clin Invest 1997; 99:1351-60.

100. El-Omar MM, Islam N, Broekman MJ, et al. The ratio of ADP- to ATP-ectonucleotidase activity is reduced in patients with coronary artery disease. Thromb Res 2005; 116:199-206.

101. Birk AV, Broekman MJ, Gladek EM, et al. Role of extracellular ATP metabolism in regulation of platelet reactivity. J Lab Clin Med 2002; 140:166-75.

102. Abraham MK, Nolte A, Reus R, et al. In vitro Study of a Novel Stent Coating Using Modified CD39 Messenger RNA to Potentially Reduce Stent Angioplasty-Associated Complications. PLoS One 2015; 10:e0138375.

103. Aho J, Helenius M, Vattulainen-Collanus S, et al. Extracellular ATP protects endothelial cells against DNA damage. Purinergic Signal 2016; 12:575-81.

104. Castilhos LG, Doleski PH, Adefegha SA, et al. Altered E-NTPDase/E-ADA activities and CD39 expression in platelets of sickle cell anemia patients. Biomed Pharmacother 2016; 79:241-6. 
105. Pulte D, Olson KE, Broekman MJ, et al. CD39 activity correlates with stage and inhibits platelet reactivity in chronic lymphocytic leukemia. J Transl Med 2007; 5:23.

106. Hohmann JD, Peter K. Activated-platelet targeting of CD39 as a potential way forward. The quest for efficient antithrombotic therapy without associated bleeding complications. Hamostaseologie 2016; 36:17-25.

107. Yamamoto K, Furuya K, Nakamura M, et al. Visualization of flow-induced ATP release and triggering of Ca2+ waves at caveolae in vascular endothelial cells. J Cell Sci 2011; 124:3477-83.

108. Buergler JM, Maliszewski CR, Broekman MJ, et al. Effects of SolCD39, a novel inhibitor of Platelet Aggregation, on Platelet Deposition and Aggregation after PTCA in a Porcine Model. J Thromb Thrombolysis $2005 ; 19: 115-22$.

109. Drosopoulos JH, Broekman MJ, Islam N, et al. Site-directed mutagenesis of human endothelial cell ecto-ADPase/soluble CD39: requirement of glutamate 174 and serine 218 for enzyme activity and inhibition of platelet recruitment. Biochemistry 2000; 39:6936-43.

110. Huttinger ZM, Milks MW, Nickoli MS, et al. Ectonucleotide triphosphate diphosphohydrolase-1 (CD39) mediates resistance to occlusive arterial thrombus formation after vascular injury in mice. Am J Pathol 2012; 181:322-33.

111. Anyanwu AC, Kanthi Y, Fukase K, et al. Tuning the Thromboinflammatory Response to Venous Flow Interruption by the Ectonucleotidase CD39. Arterioscler Thromb Vasc Biol 2019; 39:e118-e129.

112. Chaurasia SN, Kushwaha G, Pandey A, Dash D. Human platelets express functional ectonucleotidases that restrict platelet activation signaling. Biochem Biophys Res Commun 2020; 527:104-109.

113. Enjyoji K, Sevigny J, Lin Y, et al. Targeted disruption of cd39/ATP diphosphohydrolase results in disordered hemostasis and thromboregulation. Nat Med 1999; 5:1010-7.

114. Jiang ZG, Wu Y, Csizmadia E, et al. Characterization of circulating microparticle-associated CD39 family ecto-nucleotidases in human plasma. Purinergic Signal 2014; 10:611-8.

115. Muller L, Mitsuhashi M, Simms P, et al. Tumor-derived exosomes regulate expression of immune function-related genes in human T cell subsets. Sci Rep 2016; 6:20254.

116. Clayton A, Al-Taei S, Webber J, et al. Cancer exosomes express CD39 and CD73, which suppress T cells through adenosine production. J Immunol 2011; 187:676-83.

117. Zhang F, Li R, Yang Y, et al. Specific Decrease in B-Cell-Derived Extracellular Vesicles Enhances Post-Chemotherapeutic CD8(+) T Cell Responses. Immunity 2019; 50:738-750 e7.

118. Schuler PJ, Saze Z, Hong CS, et al. Human CD4+ CD39+ regulatory T cells produce adenosine upon co-expression of surface CD73 or contact with CD73+ exosomes or CD73+ cells. Clin Exp Immunol 2014; 177:531-43.

119. Schmelzle M, Splith K, Andersen LW, et al. Increased plasma levels of microparticles expressing CD39 and CD133 in acute liver injury. Transplantation 2013; 95:63-9.

120. Fan W, Wang W, Wu J, et al. Identification of CD4(+) T-cell-derived CD161(+) CD39(+) and CD39(+)CD73(+) microparticles as new biomarkers for rheumatoid arthritis. Biomark Med 2017; 11:107116.

121. Angioni R, Liboni C, Herkenne S, et al. CD73(+) extracellular vesicles inhibit angiogenesis through adenosine A2B receptor signalling. J Extracell Vesicles 2020; 9:1757900.

122. Banz Y, Beldi G, Wu Y, et al. CD39 is incorporated into plasma microparticles where it maintains functional properties and impacts endothelial activation. Br J Haematol 2008; 142:627-37. 
123. Yang M, Lu L, Kang Z, et al. Overexpressed CD39 mitigates sepsisinduced kidney epithelial cell injury via suppressing the activation of NLR family pyrin domain containing 3. Int J Mol Med 2019; 44:1707-1718.

124. Huang H, Xu R, Lin F, et al. High circulating CD39(+) regulatory T cells predict poor survival for sepsis patients. Int J Infect Dis 2015; 30:57-63.

125. Imai M, Goepfert C, Kaczmarek E, Robson SC. CD39 modulates IL-1 release from activated endothelial cells. Biochem Biophys Res Commun 2000; 270:272-8.

126. Csoka B, Nemeth ZH, Toro G, et al. CD39 improves survival in microbial sepsis by attenuating systemic inflammation. FASEB J 2015; 29:25-36.

127. Bertoncheli Cde M, Zimmermann CE, Jaques JA, et al. Increased NTPDase activity in lymphocytes during experimental sepsis. ScientificWorldJournal 2012; 2012:941906.

128. Bao R, Shui X, Hou J, et al. Adenosine and the adenosine A2A receptor agonist, CGS21680, upregulate CD39 and CD73 expression through E2F-1 and CREB in regulatory T cells isolated from septic mice. Int J Mol Med 2016; 38:969-75.

129. Liu J, Shi K, Chen M, et al. Elevated miR-155 expression induces immunosuppression via CD39(+) regulatory T-cells in sepsis patient. Int J Infect Dis 2015; 40:135-41.

130. Flynn S, Eisenstein S. Inflammatory Bowel Disease Presentation and Diagnosis. Surg Clin North Am 2019; 99:1051-1062.

131. Friedman DJ, Künzli BM, YI AR, et al. From the Cover: CD39 deletion exacerbates experimental murine colitis and human polymorphisms increase susceptibility to inflammatory bowel disease. Proc Natl Acad Sci U S A 2009; 106:16788-93.

132. Huang B, Chen Z, Geng L, et al. Mucosal Profiling of Pediatric-Onset Colitis and IBD Reveals Common Pathogenics and Therapeutic Pathways. Cell 2019; 179:1160-1176 e24.

133. Gibson DJ, Elliott L, McDermott E, et al. Heightened Expression of CD39 by Regulatory T Lymphocytes Is Associated with Therapeutic Remission in Inflammatory Bowel Disease. Inflamm Bowel Dis 2015; 21:280614.

134. Longhi MS, Moss A, Bai A, et al. Characterization of human CD39+ Th17 cells with suppressor activity and modulation in inflammatory bowel disease. PLoS One 2014; 9:e87956.

135. Doherty GA, Bai A, Hanidziar D, et al. CD73 is a phenotypic marker of effector memory Th17 cells in inflammatory bowel disease. Eur J Immunol 2012; 42:3062-72.

136. Kunzli BM, Berberat PO, Dwyer K, et al. Variable impact of CD39 in experimental murine colitis. Dig Dis Sci 2011; 56:1393-403.

137. Bonner F, Borg N, Burghoff S, Schrader J. Resident cardiac immune cells and expression of the ectonucleotidase enzymes CD39 and CD73 after ischemic injury. PLoS One 2012; 7:e34730.

138. Eckle T, Krahn T, Grenz A, et al. Cardioprotection by ecto-5'-nucleotidase (CD73) and A2B adenosine receptors. Circulation 2007; 115:1581-90.

139. Grenz A, Osswald H, Eckle T, et al. The reno-vascular A2B adenosine receptor protects the kidney from ischemia. PLoS Med 2008; 5:e137.

140. Kinsey GR, Huang L, Jaworska K, et al. Autocrine adenosine signaling promotes regulatory T cellmediated renal protection. J Am Soc Nephrol 2012; 23:1528-37.

141. Jian R, Sun Y, Wang Y, et al. CD73 protects kidney from ischemia-reperfusion injury through reduction of free radicals. APMIS 2012; 120:130-8. 
142. Hart ML, Gorzolla IC, Schittenhelm J, et al. SP1-dependent induction of CD39 facilitates hepatic ischemic preconditioning. J Immunol 2010; 184:4017-24.

143. Sun X, Imai M, Nowak-Machen M, et al. Liver damage and systemic inflammatory responses are exacerbated by the genetic deletion of CD39 in total hepatic ischemia. Purinergic Signal 2011; 7:427-34.

144. Hart ML, Henn M, Kohler D, et al. Role of extracellular nucleotide phosphohydrolysis in intestinal ischemia-reperfusion injury. FASEB J 2008; 22:2784-97.

145. Hart ML, Grenz A, Gorzolla IC, et al. Hypoxia-inducible factor-1alpha-dependent protection from intestinal ischemia/reperfusion injury involves ecto-5'-nucleotidase (CD73) and the A2B adenosine receptor. J Immunol 2011; 186:4367-74.

146. Boring YC, Flogel U, Jacoby C, et al. Lack of ecto-5'-nucleotidase (CD73) promotes arteriogenesis. Cardiovasc Res 2013; 97:88-96.

147. Aldi S, Marino A, Tomita K, et al. E-NTPDase1/CD39 modulates renin release from heart mast cells during ischemia/reperfusion: a novel cardioprotective role. FASEB J 2015; 29:61-9.

148. Ziegler M, Hohmann JD, Searle AK, et al. A single-chain antibody-CD39 fusion protein targeting activated platelets protects from cardiac ischaemia/reperfusion injury. Eur Heart J 2018; 39:111-116.

149. Sashindranath M, Dwyer KM, Dezfouli S, et al. Development of a novel strategy to target CD39 antithrombotic activity to the endothelial-platelet microenvironment in kidney ischemia-reperfusion injury. Purinergic Signal 2017; 13:259-265.

150. Duan L, Hu GH, Li YJ, et al. P2X7 receptor is involved in lung injuries induced by ischemia-reperfusion in pulmonary arterial hypertension rats. Mol Immunol 2018; 101:409-418.

151. Cai M, Huttinger ZM, He H, et al. Transgenic over expression of ectonucleotide triphosphate diphosphohydrolase-1 protects against murine myocardial ischemic injury. J Mol Cell Cardiol 2011; 51:927-35.

152. Wheeler DG, Joseph ME, Mahamud SD, et al. Transgenic swine: expression of human CD39 protects against myocardial injury. J Mol Cell Cardiol 2012; 52:958-61.

153. Xia N, Jiao J, Tang TT, et al. Activated regulatory T-cells attenuate myocardial ischaemia/reperfusion injury through a CD39-dependent mechanism. Clin Sci (Lond) 2015; 128:679-93.

154. Pommey S, Lu B, McRae J, et al. Liver grafts from CD39-overexpressing rodents are protected from ischemia reperfusion injury due to reduced numbers of resident CD4+ T cells. Hepatology 2013; 57:1597-606.

155. Ring S, Oliver SJ, Cronstein BN, et al. CD4+CD25+ regulatory T cells suppress contact hypersensitivity reactions through a CD39, adenosine-dependent mechanism. J Allergy Clin Immunol 2009; 123:1287-96 e2.

156. Mahnke K, Useliene J, Ring S, et al. Down-Regulation of CD62L Shedding in T Cells by CD39(+) Regulatory T Cells Leads to Defective Sensitization in Contact Hypersensitivity Reactions. J Invest Dermatol 2017; 137:106-114.

157. Li P, Gao Y, Cao J, et al. CD39+ regulatory T cells attenuate allergic airway inflammation. Clin Exp Allergy 2015; 45:1126-37.

158. Li P, Yang QZ, Wang W, et al. Increased IL-4- and IL-17-producing CD8(+) cells are related to decreased CD39(+)CD4(+)Foxp3(+) cells in allergic asthma. J Asthma 2018; 55:8-14.

159. Wang LL, Tang HP, Shi GC, et al. CD39/CD73 and the imbalance of Th17 cells and regulatory T cells in allergic asthma. Mol Med Rep 2013; 8:1432-8.

160. Wang LL, Tang PH, Shi CG, et al. Expression of CD39 mRNA is altered in the peripheral blood of patients with allergic asthma. Biomed Rep 2014; 2:75-78. 
161. Idzko M, C KA, Muller T, et al. Attenuated allergic airway inflammation in Cd39 null mice. Allergy $2013 ; 68: 472-80$.

162. Li P, Cao J, Chen Y, et al. Apyrase protects against allergic airway inflammation by decreasing the chemotactic migration of dendritic cells in mice. Int J Mol Med 2014; 34:269-75.

163. Becker LV, Passos DF, Leal DBR, et al. ATP signaling and NTPDase in Systemic Lupus Erythematosus (SLE). Immunobiology 2019; 224:419-426.

164. Becker LV, da Silva Pereira Saccol R, Morsch VM, et al. Activity and expression of E-NTPDase is altered in peripheral lymphocytes of systemic lupus erythematosus patients. Clin Chim Acta 2019; 488:90-97.

165. Loza MJ, Anderson AS, O'Rourke KS, et al. T-cell specific defect in expression of the NTPDase CD39 as a biomarker for lupus. Cell Immunol 2011; 271:110-7.

166. Akesson K, Tompa A, Ryden A, Faresjo M. Low expression of CD39(+) /CD45RA(+) on regulatory $\mathrm{T}$ cells (Treg ) cells in type 1 diabetic children in contrast to high expression of CD101(+) /CD129(+) on Treg cells in children with coeliac disease. Clin Exp Immunol 2015; 180:70-82.

167. Jin X, Zhang C, Gong L, et al. Altered expression of CD39 on memory regulatory T cells in type 1 diabetes patients. J Diabetes 2019; 11:440-448.

168. Garcia-Hernandez MH, Portales-Cervantes L, Cortez-Espinosa N, et al. Expression and function of P2X(7) receptor and CD39/Entpd1 in patients with type 2 diabetes and their association with biochemical parameters. Cell Immunol 2011; 269:135-43.

169. Cortez-Espinosa N, Cortes-Garcia JD, Martinez-Leija E, et al. CD39 expression on Treg and Th17 cells is associated with metabolic factors in patients with type 2 diabetes. Hum Immunol 2015; 76:622-30.

170. Zhang W, Zhou L, Dang J, et al. Human Gingiva-Derived Mesenchymal Stem Cells Ameliorate Streptozoticin-induced T1DM in mice via Suppression of T effector cells and Up-regulating Treg Subsets. Sci Rep 2017; 7:15249.

171. Chia JS, McRae JL, Thomas HE, et al. The protective effects of CD39 overexpression in multiple low-dose streptozotocin-induced diabetes in mice. Diabetes 2013; 62:2026-35.

172. Mandapathil M, Boduc M, Roessler M, et al. Ectonucleotidase CD39 expression in regional metastases in head and neck cancer. Acta Otolaryngol 2018; 138:428-432.

173. Mandapathil M, Szczepanski MJ, Szajnik M, et al. Increased ectonucleotidase expression and activity in regulatory T cells of patients with head and neck cancer. Clin Cancer Res 2009; 15:6348-57.

174. Pulte D, Furman RR, Broekman MJ, et al. CD39 expression on T lymphocytes correlates with severity of disease in patients with chronic lymphocytic leukemia. Clin Lymphoma Myeloma Leuk 2011; 11:367-72.

175. Cai XY, Wang XF, Li J, et al. High expression of CD39 in gastric cancer reduces patient outcome following radical resection. Oncol Lett 2016; 12:4080-4086.

176. Cai X-Y, Wang X-F, Li J, et al. Overexpression of CD39 and high tumoral CD39+/CD8+ ratio are associated with adverse prognosis in resectable gastric cancer. International journal of clinical and experimental pathology 2015; 8:14757-14764.

177. Leone RD, Emens LA. Targeting adenosine for cancer immunotherapy. J Immunother Cancer 2018; $6: 57$.

178. Cai XY, Ni XC, Yi Y, et al. Overexpression of CD39 in hepatocellular carcinoma is an independent indicator of poor outcome after radical resection. Medicine (Baltimore) 2016; 95:e4989.

179. Parodi A, Battaglia F, Kalli F, et al. CD39 is highly involved in mediating the suppression activity of tumor-infiltrating CD8+ T regulatory lymphocytes. Cancer Immunol Immunother 2013; 62:851-62. 
180. Sundström P, Stenstad H, Langenes V, et al. Regulatory T Cells from Colon Cancer Patients Inhibit Effector T-cell Migration through an Adenosine-Dependent Mechanism. Cancer Immunol Res 2016; 4:183-93.

181. Retseck J, Nasr A, Lin Y, et al. Long term impact of CTLA4 blockade immunotherapy on regulatory and effector immune responses in patients with melanoma. 2018; 16:184.

182. Zheng Y, Li Y, Tang B, et al. IL-6-induced CD39 expression on tumor-infiltrating NK cells predicts poor prognosis in esophageal squamous cell carcinoma. Cancer Immunol Immunother 2020.

183. Yin Z, Li C, Wang J, Xue L. Myeloid-derived suppressor cells: Roles in the tumor microenvironment and tumor radiotherapy. Int J Cancer 2019; 144:933-946.

184. Li J, Wang L, Chen X, et al. CD39/CD73 up-regulation on myeloid-derived suppressor cells via TGF$\beta$-mTOR-HIF-1 signaling in patients with non-small cell lung cancer. Oncoimmunology 2017; 6:00-00.

185. Limagne E, Euvrard R, Thibaudin M, et al. Accumulation of MDSC and Th17 Cells in Patients with Metastatic Colorectal Cancer Predicts the Efficacy of a FOLFOX-Bevacizumab Drug Treatment Regimen. Cancer Res 2016; 76:5241-52.

186. Li L, Wang L, Li J, et al. Metformin-Induced Reduction of CD39 and CD73 Blocks Myeloid-Derived Suppressor Cell Activity in Patients with Ovarian Cancer. Cancer Res 2018; 78:1779-1791.

187. Sun X, Wu Y, Gao W, et al. CD39/ENTPD1 expression by CD4+Foxp3+ regulatory T cells promotes hepatic metastatic tumor growth in mice. Gastroenterology 2010; 139:1030-40.

188. Jackson SW, Hoshi T, Wu Y, et al. Disordered purinergic signaling inhibits pathological angiogenesis in cd39/Entpd1-null mice. Am J Pathol 2007; 171:1395-404.

189. Sun X, Han L, Seth P, et al. Disordered purinergic signaling and abnormal cellular metabolism are associated with development of liver cancer in Cd39/ENTPD1 null mice. Hepatology 2013; 57:205-16.

190. Künzli BM, Rath S, Käser S, et al. Impact of CD39 and purinergic signalling on the growth and metastasis of colorectal cancer. Purinergic Signalling 2011; 7:231-241.

191. Bastid J, Regairaz A, Bonnefoy N, et al. Inhibition of CD39 enzymatic function at the surface of tumor cells alleviates their immunosuppressive activity. Cancer immunology research 2015; 3:254-265.

192. Li XY, Moesta AK, Xiao C, et al. Targeting CD39 in Cancer Reveals an Extracellular ATP- and Inflammasome-Driven Tumor Immunity. Cancer Discov 2019; 9:1754-1773. 